Área Abierta. Revista de comunicación

audiovisual y publicitaria

ISSN: 2530-7592 / ISSNe: 1578-8393

\title{
Análisis del discurso científico del cambio climático en la fotografía de El Mundo y El País
}

\author{
Ismael García Herrero ${ }^{1}$ y Nuria Navarro Sierra ${ }^{2}$
}

Recibido: 26 de agosto de 2020 / Aceptado: 12 de septiembre de 2020

Resumen. El objetivo de esta investigación es conocer las principales funciones y características que la imagen fotoperiodística cumple en las versiones digitales de El País y El Mundo y explorar la forma en que estos medios enmarcan sus fotografías en las noticias sobre cambio climático. Los resultados indican el predominio de la personificación del cambio climático en los líderes políticos, con el presidente Trump como presencia mayoritaria. Las fotografías de agencia o de archivo son la fuente primordial de las noticias y también se aprecia una relación entre estas y el texto noticioso. Como aspectos más técnicos se podría señalar la primacía de colores fríos sobre los cálidos y un tratamiento cualitativo muy similar en los diarios estudiados.

Palabras clave: fotoperiodismo; cambio climático; fotografía; comunicación científica; imagen

\section{[en] Analysis of the Scientific Discourse of Climate Change in El Mundo and El Pais Photography}

\begin{abstract}
The objective of this research is to know the main characteristics and functions that the photojournalistic image fulfills within the digital version in El País and El Mundo, and to explore the way in which these Spanish media frame their photographs in the news on climate change. The results indicate the predominance of the personification of climate change in foreign political leaders, with US President Donald Trump as the majority presence. Agency or archive photographs are the primary source of news and there is also a relationship between them and the news text. As more technical aspects, the primacy of cold colors over warm colors and a very similar qualitative treatment in the studied newspapers could be pointed out.
\end{abstract}

Key words: Photojournalism; Climate Change; Photography; Scientific Communication; Image

Sumario. 1. Introducción. 2. Fundamentación, metodología y objetivos. 3. Resultados. 4. Conclusiones y discusión. 5. Referencias bibliográficas.

Cómo citar. García Herrero, Ismael y Navarro Sierra, Nuria (2020). Análisis del discurso científico del cambio climático en la fotografía de El Mundo y El País. Área Abierta. Revista de comunicación audiovisual y publicitaria 20 (3), 371-384, http://dx.doi.org/10.5209/arab.71208

\footnotetext{
Universidad de Valladolid (España)

E-mail: ismael.garcia@uva.es

ORCID: https://orcid.org/0000-0003-0984-2450

2 Universidad Rey Juan Carlos (España)

E-mail: nuria.navarro.sierra@urjc.es

ORCID: https://orcid.org/0000-0002-1431-1534
} 


\section{Introducción}

El año 2019 ha sido el más caluroso en Europa y el segundo más cálido en el planeta desde que comenzaron los registros oficiales en la segunda mitad del siglo XIX. De acuerdo con análisis independientes de la NASA y del Servicio de Cambio Climático Copernicus, el sistema desarrollado por la Unión Europea de observación de la Tierra, son "señales de alarma incuestionables". El aumento de la temperatura media se ha acentuado en los últimos treinta y siete años, ya que dieciocho de los diecinueve años más calurosos registrados han sucedido en este siglo, algo que constituye un hecho sin precedentes. La Organización Meteorológica Mundial - WMO por sus siglas en inglés - lleva alertando en sus últimos informes - 2017-que las concentraciones de dióxido de carbono y de metano están aumentando vertiginosamente hasta alcanzar nuevos récords y que ambas contribuyen al cambio climático.

Los modelos climáticos de la Met Office - el Servicio Meteorológico Nacional del Reino Unido-, estiman que en 2020 la temperatura media global se situará entre $0.99^{\circ} \mathrm{C}$ y $1.23^{\circ} \mathrm{C}$ por encima de los niveles preindustriales, con una proyección media para los doce meses de $1.11^{\circ} \mathrm{C}$. Durante el periodo que se ha denominado como 'antropoceno', la humanidad ha irrumpido como una nueva fuerza capaz de intervenir en los procesos fundamentales de la biosfera (Crutzen; Stoermer, 2000: 12-13).

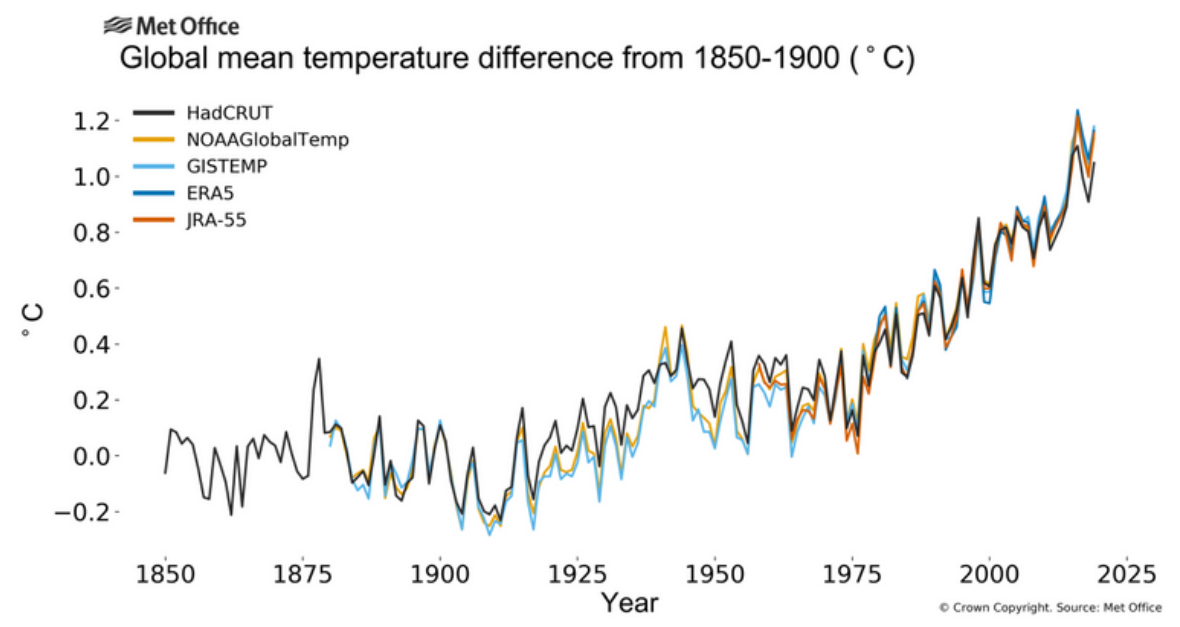

Imagen 1. Evolución de las anomalías de la temperatura global para diferentes agencias meteo-climatológicas. [Fuente: Met Office]

La Organización de las Naciones Unidas ha alertado numerosas veces sobre aumentos de temperatura "sin precedentes" en la Tierra debido al cambio climático, entendido como un cambio de clima atribuido directa o indirectamente a la actividad humana que altera la composición de la atmósfera mundial y que se suma a la variabilidad natural del clima observada durante periodos de tiempo comparables (Convención Marco de las Naciones Unidas sobre el Cambio Climático, 1992: 3) y al efecto de la actividad humana sobre el sistema climático global que, siendo consecuencia del cambio global afecta, a su vez, a otros procesos fundamentales del 
funcionamiento del sistema Tierra (Duarte, 2006: 23). Este cambio global se entiende como el conjunto de cambios ambientales afectados por la actividad humana, con especial referencia a cambios en los procesos que determinan el funcionamiento del sistema Tierra (Duarte et al., 2006: 23).

En octubre de 2018, el Panel Intergubernamental de Expertos sobre el Cambio Climático — IPCC_- órgano encargado de evaluar los conocimientos científicos relativos al cambio climático, publicó un informe especial sobre los impactos del calentamiento global con respecto a los niveles preindustriales. En dicha publicación se exponen las trayectorias correspondientes que deberían seguir las emisiones mundiales de gases de efecto invernadero, en el contexto del reforzamiento de la respuesta mundial a la amenaza del cambio climático, el desarrollo sostenible y los esfuerzos por erradicar la pobreza. El informe de síntesis del Sexto Informe de Evaluación finalizará en el año 2022.

Durante los años setenta y principios de los ochenta del siglo pasado, ya existían numerosas evidencias científicas del cambio climático, pero a los medios de comunicación se trasladaban en forma de meras y dispersas referencias. Las investigaciones sobre las coberturas informativas, fundamentalmente en países anglosajones, comenzaron midiendo el seguimiento del cambio climático cuando sus causas empezaron a identificarse como una amenaza ambiental (Corbett; Young; Davis, 2009: 13). Hasta más de una década después, no llegaría a realizarse en nuestro país una cobertura representativa. Pero la sociedad española no identificó el cambio climático como un objeto de interés público hasta mediados de los años noventa; si bien, anteriormente, estaba ya considerado como tema grave en las esferas científicas, ecologistas o políticas (Fernández-Reyes, 2010: 11; Meira, 2008: 20).

La evolución en la cobertura informativa sobre el cambio climático comenzó con una primera alerta de los científicos y, acto seguido, de los ecologistas, a los que se sumaron los medios de comunicación hasta trasladar el problema a la opinión pública.

Aunque la ciencia y la política del cambio climático han determinado el modo de informar de los medios y la comprensión del público, el periodismo y la preocupación pública también han contribuido a conformar la ciencia climática y las decisiones políticas (Boykoff, 2009: 120).

Lo referido anteriormente enlaza con las particularidades internas en el ejercicio del periodismo y las peculiaridades de las empresas comunicativas que se retroalimentan de manera compleja y no tratan de manera homogénea la cobertura del tema en cuestión (Carvalho; Burgess, 2005; Fernández-Reyes, 2010).

Los estudios sobre la cobertura mediática del cambio climático son cada vez más numerosos (Doulton; Brown, 2009) existen también varias investigaciones centradas en el papel de los medios y los periodistas científicos (Boykoff, 2007; Cabeza; Gómez, 2012 Fernández-Reyes; Mancinas-Chávez, 2013) en cambio, los estudios sobre el análisis fotoperiodístico de discursos científicos son muy escasos.

Por otra parte, la importancia informativa de la imagen fotoperiodística, respaldada desde el punto de vista doctrinal y empírico, como ponen de manifiesto los trabajos de Norbert Küpfer (1991: 4) sobre áreas de atención en la lectura de periódicos, demuestran el poder captador de la fotografía hacia la lectura de los textos y la superioridad de la imagen en cuanto a rapidez de comprensión y memorización por parte del lector. En términos de contenido informativo, la fotografía aporta un conjunto de 
datos valorativos, codificados y plasmados de manera autónoma, conformando una estructura independiente, aunque complementaria de la textual.

Existen impedimentos en las imágenes para articular el conocimiento del cambio climático con las acciones urgentes, ya que, como señala Doyle (2011), el tiempo ecológico excede el tiempo de reloj. Mientras que las imágenes dan la sensación de alejar la urgencia del problema, las evidencias del pasado y del presente no dan a conocer lo que no podemos ver como algo característico del cambio climático. Habría que persuadir al público de que no todos los problemas ambientales se pueden ver (Doyle, 2007: 147).

Tal vez por las complicaciones señaladas, Sheppard (2005) propone unos estándares éticos en la visualización del cambio climático: la representación de las incertidumbres a través de visualizaciones alternativas, la presentación de los distintos escenarios del problema — global, regional y local—, la información sobre los aspectos no visibles y una correcta dramatización.

Otra clasificación es la que sugiere Manzo (2010), quien ordena la iconografía del cambio climático en tres categorías, según lo que representa la imagen: planeta, medio ambiente y seres vivos. En la categoría de medio ambiente, el derretimiento de los glaciares es la iconografía dominante y los osos polares en la de seres vivos.

\section{Fundamentación, metodología y objetivos}

La imagen fotoperiodística es un objeto de estudio complejo que puede ser abordado desde múltiples vertientes. El objetivo general del presente artículo es conocer las principales características y funciones que este tipo de imagen cumple en las ediciones digitales de los diarios generalistas de mayor audiencia en España que según los datos de la empresa comScore, medidor oficial del mercado, se trata de El País y El Mundo. Para ello, el presente estudio explora la forma en que ambos medios enmarcan sus fotografías en las noticias sobre cambio climático. Concretamente, mediante una propuesta propia de plantilla de análisis descriptivo y de una lectura interpretativa que se realiza a través de un análisis de contenido de la imagen fotoperiodística. La muestra cuenta con una selección final de ciento sesenta y cuatro fotografías que corresponden con el total de noticias que incluyen el término "cambio climático" en el titular, en los subtítulos o los antetítulos de las noticias publicadas entre abril de 2016 y abril de 2017.

El análisis se estructura en torno a tres elementos clave del proceso comunicativo: 1) Un análisis descriptivo de los elementos formales de la imagen; 2) La lectura interpretativa de las imágenes analizadas; y 3) La finalidad de la imagen y la valoración global comunicativa dentro de la noticia.

De este modo, el trabajo aborda un conjunto de procedimientos descriptivos e interpretativos fotográficos, que se originan en procesos comunicativos previamente registrados. En definitiva, la finalidad es procesar los datos más relevantes sobre las condiciones que puedan darse para su empleo posterior, partiendo de técnicas cuantitativas y cualitativas.

Se contempla un marco teórico que pretende servir como referencia en la interpretación de los resultados obtenidos, para la elaboración de un esquema teórico que permita un análisis de las imágenes fotoperiodísticas sobre el cambio climático de una forma eficaz. 
Hay que señalar que existe una amplia bibliografía sobre el análisis de la imagen fotográfica que sirve de fundamento teórico esencial para la presente investigación.

Sin ánimo de desestimar otras muchas y considerables aportaciones, destacan como referencia por su importante influencia las obras de Roland Barthes ${ }^{3}$. Y con una visión periodística podemos encontrar en España los libros de Lorenzo Vilches ${ }^{4}$ y Manuel Alonso Erausquin ${ }^{5}$.

También se plantea la adecuación de la teoría de la agenda setting (McCombs and Shaw, 1972), la teoría del encuadre o framing (Entman 1993) y la teoría del análisis del marco (Goffman, 1974).

Las imágenes fotoperiodísticas pueden examinarse como documentos que actúan como un elemento importante de una colectividad. Partiendo de las particularidades de las comunicaciones científicas, el presente artículo analiza el papel que desempeñan las fotografías sobre el cambio climático dentro del discurso científico de la prensa española generalista de referencia, en su versión digital, durante doce meses.

Los modelos de análisis de contenidos, como el que se realiza en este trabajo de investigación, se componen de un análisis morfológico que divide las características técnicas, formales y de composición de la imagen.

\section{Resultados}

Antes de presentar los resultados del análisis, se debe destacar que el género periodístico predominante entre los artículos analizados es el noticioso en ambos medios, con un cuarenta y seis por ciento. Esto viene a reconocer una de las carencias de la información medioambiental: la gran dependencia de los sucesos, frente a la escasa explicación de los procesos, que tendrían lugar en los reportajes.

También resulta significativo el alto porcentaje de artículos de opinión en ambos medios — dieciocho por ciento-, lo que indica que estamos ante un asunto de interés para el público que, pese al consenso científico, suscita frecuentes valoraciones en la opinión pública. Cabe destacar que, durante el análisis de contenido, se ha observado en ambos medios que varias imágenes se repiten en diversas piezas periodísticas. Es decir, no se trata de recursos fotográficos realizados expresamente para una noticia, sino recursos 'generalistas' que se usan para varias unidades informativas, incluso de temas distintos relacionados o no con el cambio climático.

Es importante señalar que la dinámica actual de la estructura fotoperiodística tiende a cambiar las imágenes informativas tomadas por fotógrafos contratados o de la plantilla, para sustituirlas por imágenes estereotipadas que proceden en su mayoría de agencias de prensa.

Por último, merece la pena constatar la gran dependencia de las agencias de imágenes. En el caso de El Mundo las fotografías representan el ochenta y cuatro por ciento y en El País, el setenta y nueve por ciento del total de imágenes analizadas. La mayor parte de estas presentan lugares muy alejados geográficamente de España.

\footnotetext{
"Retórica de la imagen” (1964) y "La cámara lúcida" (1980).

"La lectura de la imagen” (1983) y “Teoría de la imagen fotoperiodística” (1993).

"Fotoperiodismo: formas y códigos" (1995) en el que sintetiza una parte importante de las teorías anteriores, además de aportar una útil herramienta teórica para el análisis de la fotografía informativa.
} 


\subsection{Lectura descriptiva}

Para el análisis se han tenido en cuenta varios de los elementos que conforman una imagen; el principal tema representado, los elementos formales que la componen - prestando especial atención a la gama cromática dominante- y los elementos textuales, por considerarse claves en la transmisión de valores connotativos. A continuación, se presentan aquellos de los que se han obtenido más información.

\subsubsection{Tema Principal}

En las imágenes analizadas aparecen los siguientes temas: personas — cuarenta y cinco por ciento-, en gran parte políticos o activistas; seguido por lugares - treinta y cuatro por ciento-, que en su mayoría son localizaciones alejadas geográficamente de España, de este modo, aparecen los polos o sitios con climas extremos; acontecimientos - catorce por ciento- como manifestaciones o reuniones, como la de la Cumbre del Clima de Marrakech; animales — cinco por ciento—; y, por último, objetos - dos por ciento-, especialmente instrumentos científicos.

El reparto de las temáticas entre los diarios no es igualitario, El País concentra un gran porcentaje de sus fotografías entre lugares y personas, mientras que El Mundo también muestra interés en acontecimientos concretos, como puede verse en la siguiente gráfica.

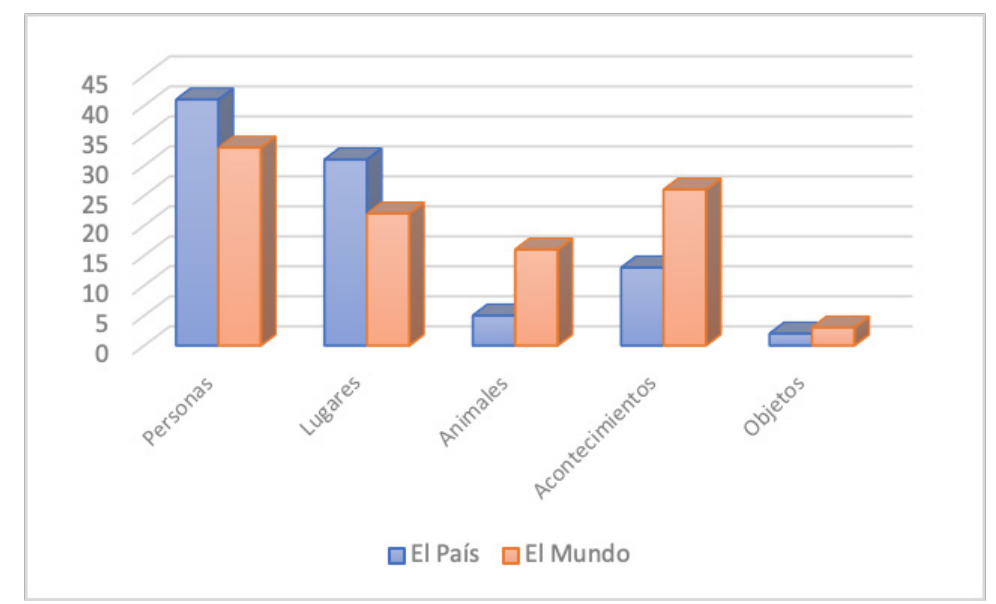

Imagen 2. Tema principal más tratado y comparativa entre ambos diarios.

[Fuente: Elaboración Propia]

\subsubsection{Elementos formales}

La mayoría de las imágenes analizadas aportan un significado, transmiten alguna connotación a través de los elementos formales. Sin embargo, es importante entender que no se trata de imágenes de estudio, y que no se dispone de demasiado tiempo para su ejecución.

En cuanto a los esquemas visuales, prima la asimetría compositiva, algo que es comprensible al tratarse de una imagen fotoperiodística. 
El uso del plano medio y medio-corto destaca en el encuadre, con un sesenta y ocho por ciento del total, para retratar personalidades - en su mayoría políticos-, mientras que el plano general o el de conjunto representan un dieciocho por ciento. El resto del porcentaje se divide entre grandes planos generales y planos detalles.

Por otro lado, los ángulos y las ópticas utilizadas en la mayoría de los casos son estándares - mostrando una visión muy próxima al campo visual del ojo humano-, siendo uno de los elementos formales que menos variación presenta.

En relación con la gama cromática dominante, resalta el amplio porcentaje en el uso de colores fríos - setenta por ciento-, aquellos que se encuentran en el círculo cromático entre el azul y el verde. Estas imágenes son mayoritariamente usadas en prensa para retratar a líderes políticos, ruedas de prensa y fotografías urbanas e invernales. En contraposición, nos encontramos con el uso de colores cálidos, utilizados solo en un diez por ciento de las fotografías, utilizado principalmente en fotografías de paisajes de zonas áridas, mientras que el contraste de colores se encuentra en un veinte por ciento de las imágenes analizadas, sobre todo en fotografías de naturaleza.

\subsubsection{Elementos textuales}

Los elementos textuales a los que acompañan las imágenes fotoperiodísticas son de suma importancia a la hora de identificar los componentes toponímicos y cronológicos. En el caso del nivel iconográfico, se han utilizado en el noventa y ocho por ciento de los casos. La función más importante que se da en este apartado es la de anclaje, el texto limita y reduce las posibilidades significativas de la imagen. El mensaje lingüístico simplifica la imagen a la monosemia, sobre todo en el caso de los pies de foto, determinando su sentido y orientando su lectura, de esta forma se reducen las posibilidades significativas de la imagen.

En cuanto a la personificación en los líderes políticos, con Donald Trump como máximo exponente, hay una relación clara entre imagen y texto en los diarios analizados. En la gran mayoría de ocasiones el texto incluido en el titular relaciona al presidente americano con la controversia sobre el cambio climático, la polémica y la ignorancia ante las evidencias científicas. Pero, en contraposición, en el análisis de los elementos textuales se han encontrado también diversos ejemplos de cómo los medios analizados buscan atraer la atención del lector, más que aportar una imagen visual acorde con el contenido científico que se está difundiendo. Con este análisis se puede concluir que los elementos textuales son imprescindibles para agilizar el trabajo de identificación del contenido de las fotografías. 


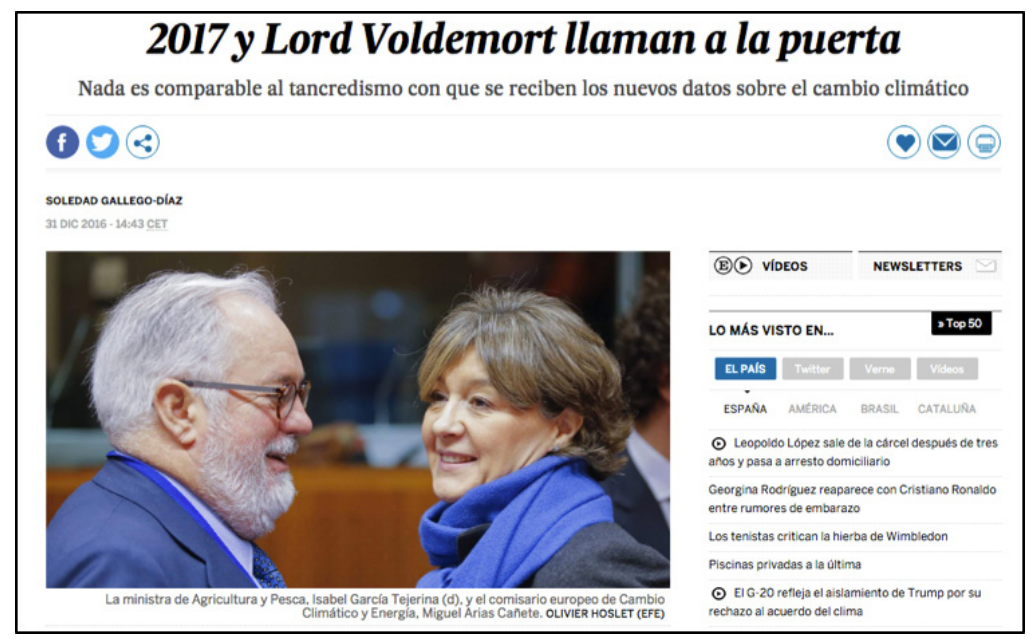

Imagen 3. Líderes políticos españoles junto a un titular que busca atraer la atención del lector

[Fuente: El País, 31/12/2016]

\section{Cambio climático, 'un cuento chino'}

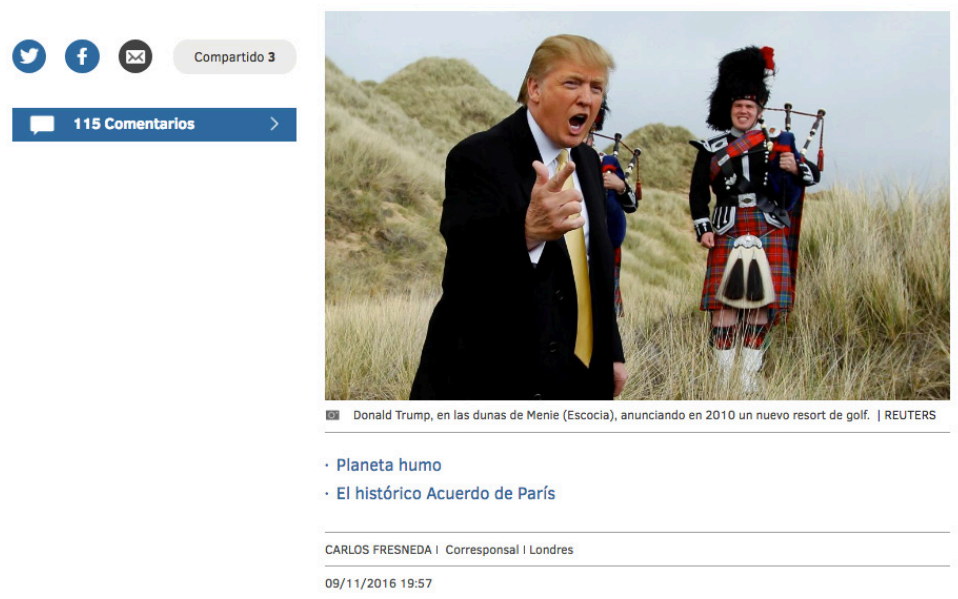

Imagen 4. Personificación del cambio climático en los líderes gubernamentales con Donald Trump como presencia mayoritaria y polémica [Fuente: El Mundo, 09/11/2016]

\subsection{Lectura Interpretativa}

En relación con la lectura interpretativa de las imágenes analizadas, debemos señalar que el propósito principal de las imágenes fotoperiodísticas en ambos medios es claramente informativo. Los dos diarios sitúan el referente principal en un contexto fácilmente interpretable, pero generalmente alejado geográficamente de España imagen 3 -, como la Isla de Pascua, Tanzania o Pakistán. 


\section{El sur de España se desertizará si no se reducen las emisiones}

El cambio climático alterará el paisaje mediterráneo en apenas 80 años

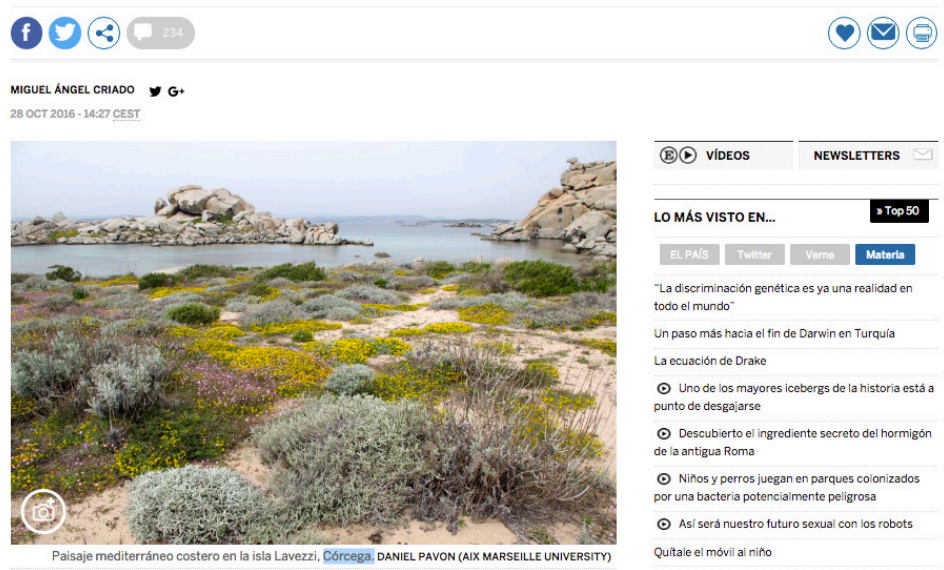

Imagen 5. Utilización de una imagen de Córcega para ilustrar una noticia sobre la desertización del sur de España [Fuente: El País, 28/08/2016]

Los datos obtenidos de las fotografías fotoperiodísticas, en relación con esta dimensión, hacen referencia al concepto del cambio climático, así como a la identificación de sus causas y consecuencias.

La percepción general de la imagen fotoperiodística en ambos diarios pretende concienciar al público de los peligros del cambio climático y advertir de sus efectos. Las connotaciones emocionales son algo alarmistas, pero a la vez tratan de concienciar al espectador de la acción antropocéntrica del cambio climático y la imagen se utiliza como un ejemplo de los peligros o para poner cara, bien a los científicos que son quienes investigan y alertan de este fenómeno o, sobre todo, a los políticos que son quienes deben tomar las decisiones al respecto. Una línea de actuación que comparten con las redes sociales (Segado-Boj; Díaz-Campo; Navarro-Sierra, 2020).

Las imágenes fotoperiodísticas transmiten en los dos medios una imagen estereotipada, tanto de las fotografías de lugares, generalmente afectados por el cambio climático, como de la gestualidad triunfal de los políticos, donde predomina la seguridad y la cercanía, con la utilización mayoritaria de planos medios y cortos. Por ello, puede afirmarse que se trata de una imagen arquetípica y previsible del cambio climático, por ser la convencionalmente transmitida y asumida durante años.

En general, las imágenes pretenden transmitir conciencia por el medio ambiente, para que el espectador vea que el cambio climático es real, aunque para ello se utilicen imágenes estereotipadas. En algunas ocasiones se pretende transmitir miedo o temor ante las consecuencias, utilizando la imagen con la intención de animar al espectador a frenar el cambio climático. 


\section{El infierno literario de Trump}
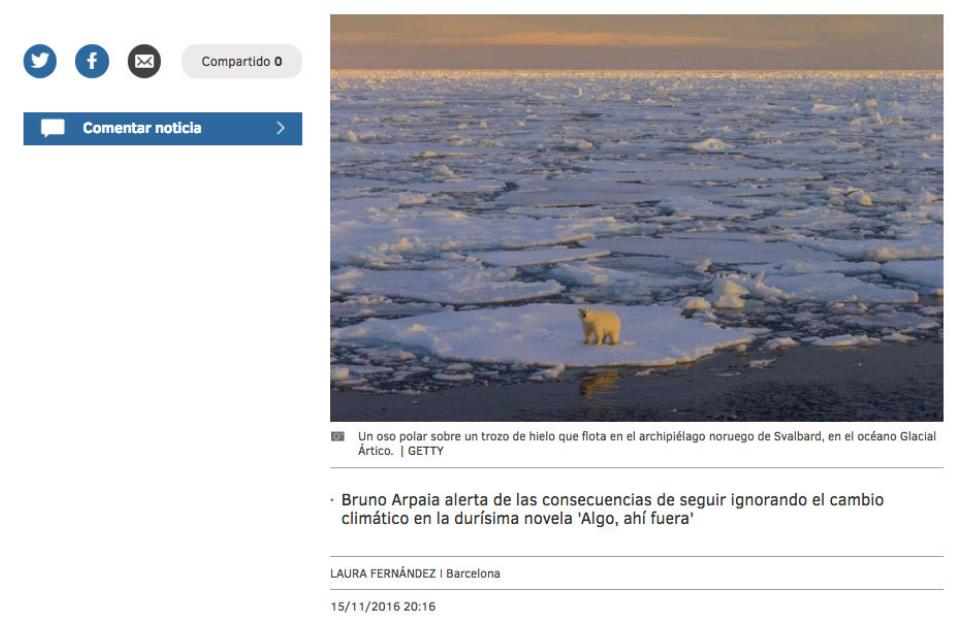

Imagen 6. Fotografía que ilustra las consecuencias del cambio climático

[Fuente: El Mundo, 15/11/2016]

Por el contrario, en las fotografías en las que aparecen personas, en su mayoría políticos, las reacciones que se pretenden provocar son las de cercanía y grandiosidad, con la utilización de angulares próximos a la visión humana, planos medios y cortos, algo picados, que hacen que el sujeto aparezca realzado. En ocasiones, en contraposición con artículos críticos a las políticas internacionales, sobre todo del presidente Trump, la imagen no refleja la negatividad del texto, mostrando a los líderes políticos desde una visión cerca al espectador. Esto refrenda la idea de que uno de los principales hitos en la cobertura del cambio climático tiene que ver con la política internacional.

La mayor parte de las imágenes que abordan el cambio climático se refieren a hechos o sucesos no cotidianos que se suponen desconocidos por el espectador y que permiten aportar un contexto necesario. El contexto sociológico y político es esencial para entender el uso actual de la imagen fotoperiodística del cambio climático. Cabe decir que la línea ideológica del medio, en el actual contexto comunicativo, no incide de forma determinante en la publicación de imágenes relativas al cambio climático. Sin embargo, la construcción cultural y periodística del tema se guía por un claro patrón político internacional, reflejado en la fotografía.

En un análisis de contenido no se puede olvidar el contexto, especialmente para la fotografía de prensa, ya que supone el marco de referencia en el que se sitúa una fotografía: un evento de carácter social o político determinado, un suceso cultural o natural, la época en la que se sitúa la noticia, el espacio, o el tiempo determinado son los indicadores fundamentales del contexto.

\subsection{Finalidad de la imagen}

En esta última parte del análisis de contenido se trata de comprobar si las imágenes fotoperiodísticas del cambio climático transmiten emociones, sentimientos o indu- 
cen a la reflexión y la concienciación, si forman una visión distorsionada de las comunicaciones científicas a las que hacen referencia los artículos o si son un medio idóneo para informar de manera clara y directa sobre cambio climático.

En cuanto a la connotación de las imágenes del cambio climático en ambos medios, queremos destacar que estas surgen como resultado del conjunto de deliberaciones que, en base a su intencionalidad, lleva a cabo el fotoperiodista en el momento de su creación. Nos referimos, entre otras, a la elección del objeto o sujeto a fotografiar, la habilidad técnica del propio autor, la selección del objetivo, además de las elecciones estéticas y compositivas del fotoperiodista. Estas elecciones traspasan el objetivo de la cámara y muestran datos reveladores sobre el autor. De esta forma, podemos afirmar que las imágenes fotoperiodísticas del cambio climático poseen connotaciones a nivel morfológico, pero son un medio idóneo para informar de manera clara y directa de las consecuencias del cambio climático, aunque no lleguen a abordar correctamente las causas.

\section{Conclusiones y discusión}

El esquema propuesto permite descomponer las fases de la lectura y el análisis de las imágenes fijas para obtener datos cuantitativos y cualitativos, que permitan la redacción y el resumen, así como para la asignación de unas palabras clave para su incorporación en una base de datos. También permite encontrar elementos de significación en las diferentes fases del análisis. A partir de los resultados anteriormente expuestos se pueden inferir las siguientes conclusiones: 1) Siguiendo la clasificación de seres vivos propuesta por Manzo (2010), a la que se hace referencia en la introducción, esta investigación concluye que se ha pasado de la iconografía del oso polar, a la personificación en los líderes políticos, con Donald Trump como máximo exponente. Estas muestran una visión fotográfica cercana, con retratos y el uso de planos medios y cortos, aportando la sensación de proximidad al espectador; 2) El principal pico noticioso que ha tenido el periodo analizado ha sido noviembre de 2016, que coincidió con la Cumbre del Clima de Marrakech, celebrada entre el siete y el dieciocho de dicho mes en la capital marroquí. Aunque hay que señalar que la mayor parte de las fotografías que acompañaban a las noticias, que contenían el término "cambio climático" en ese pico informativo, hacían referencia a la victoria electoral de Donald Trump en Estados Unidos, quien ha copado gran parte de las imágenes alusivas al cambio climático durante la última parte del periodo analizado. Por lo que se puede verificar la hipótesis referente a que uno de los principales hitos en la cobertura del cambio climático tiene que ver con la política internacional; 3) En cuanto a la lectura interpretativa, las fotografías tienen un tratamiento cualitativo bastante similar en los dos medios y transfieren una imagen estereotipada y previsible del cambio climático que busca atraer la atención del lector, más que aportar una imagen visual acorde con el contenido científico que se está difundiendo; 4) Dentro de este mismo análisis cabe destacar la existencia de diversas connotaciones en la imagen fotoperiodística del cambio climático y que esta puede encontrarse tanto en los elementos morfológicos y formales de la imagen, como en las formas de composición y en los propios signos fotográficos. Es reseñable la importancia del pie de foto, que se hace indispensable para conocer los elementos que la imagen no muestra - en su mayoría el tiempo, el lugar, el evento al que hace referencia la fotografía y el 
significado- - Al ser elementos que muchas veces solo conoce el fotoperiodista y/o el editor del medio, pensamos que es necesaria una interacción entre investigador y fotógrafo para realizar correctamente un análisis científico sin errores de indización; y 5) La principal lectura interpretativa que se extrae de los resultados anteriores es que el discurso de la imagen fotoperiodística se centra en la repercusión del cambio climático sobre la naturaleza, en lugares alejados geográficamente de nuestro país y sobre los acuerdos políticos internacionales. La mayoría de las imágenes muestran acontecimientos del presente para representar sus causas y, sobre todo, consecuencias futuras del cambio climático.

En cuanto a las perspectivas futuras, a partir de este artículo podrían proponerse alternativas de investigación poco exploradas en fotoperiodismo, y más concretamente dentro del periodismo científico. Entre ellas se propone la realización de estudios comparativos sobre el tratamiento de la imagen fotoperiodística en los medios de referencia de países de nuestro ámbito geográfico y de otros continentes. Asimismo, se estima que podría tener interés la realización de trabajos de planteamiento histórico, para analizar el tratamiento y la evolución de la fotografía periodística sobre el cambio climático en diferentes épocas.

Sería interesante conocer si el análisis de contenido que se realiza en esta investigación podría ser extrapolado a otros medios periodísticos de similar perfil y de referencia a nivel internacional. E incluso se podría hacer una comparativa del análisis de la imagen fotoperiodística del caso español, con el tratamiento que hayan realizado otros medios de información en el ámbito internacional sobre el cambio climático. Es importante que esta investigación no se quede dentro de las fronteras españolas, ya que trabajos similares se podrían abordan también en otras latitudes y esas contribuciones se pueden tomar en consideración para crear una imagen global de la utilización fotoperiodística del cambio climático.

Otra posible vía de investigación, relacionada con este trabajo, se centraría en el estudio de la imagen de otras plataformas en Internet, ajenas a las páginas web de los periódicos de información generalista.

A modo de conclusión general, habría que analizar si el fotoperiodismo sigue teniendo una importante influencia en la imagen que se publica en la prensa digital sobre temas científicos. A través de Internet, los propios organismos de investigación, muchos de ellos con pequeños departamentos de comunicación o periodistas especializados dedicados a ello, pueden transmitir directamente al público sus informaciones a través de blogs o redes sociales en tiempo real. Incluso los propios científicos están cada vez más concienciados con la divulgación y raro es el grupo de investigación en el que no se tomen imágenes de las actividades que están realizando o los proyectos de campo o laboratorio que llevan a cabo. ¿Se debería replantear el papel del fotoperiodismo? ¿Un científico, con una formación superior en ciencias de la información, puede comunicar mejor que un titulado en esta rama especializado en ciencia?

Todavía queda mucho por hacer en el campo de la imagen fotoperiodística en los medios de comunicación y más concretamente en el tema que nos ocupa. Todos los componentes que rodean la imagen, fundamentalmente fotoperiodistas y directivos de las empresas periodísticas, deben tomar en consideración la importancia de aunar esfuerzos para conseguir que podamos comprender un fenómeno tan complejo como el cambio climático, definido ya como el problema ambiental más importante al que se enfrenta la humanidad y dejar una generosa herencia a las generaciones futuras. 


\section{Bibliografía}

Boykoff, M. T., \& Boykoff, J. M. (2007). "Climate Change and Journalistic Norms: A case-study of US Mass-Media Coverage. Geoforum, 38(6), pp. 1190-1204. https://doi. org/10.1016/j.geoforum.2007.01.008

Boykoff, M. T. (2009). "El caso del cambio climático. Los medios y la comunicación científica”. Infoamérica, 1, 117-127. Recuperado de: https://dialnet.unirioja.es/servlet/articulo? codigo $=3910914$

Cabeza, J., \& Gómez, S. (2012). "El diseño de la realidad televisiva en el documental de naturaleza: El Hombre y la Tierra. Serie Venezolana” (Félix Rodríguez de la Fuente,1974). Estudios sobre el Mensaje Periodístico, 18(1), pp. 275-291. https://doi.org/10.5209/rev_ ESMP.2012.v18.n1.39370

Carvalho, A., \& Burgess, J. (2005). "Cultural Circuits of Climate Change in UK Broadsheet Newspapers, 1985-2003”. Risk Analysis: An International Journal, 25(6), pp. 14571469. https://doi.org/10.1111/j.1539-6924.2005.00692.x

Corbett, J. B., Young, L. E., \& Davis, B. L. (2009). "Teoría del conflicto e información sobre el cambio climático: interacción entre medios, ciencia, política, industria y audiencias". Infoamérica: Iberoamerican Communication Review, (1), pp. 5-23. Recuperado de: https://dialnet.unirioja.es/servlet/articulo? codigo $=3907213$

Crutzen, P.J. and Stoermer, E.F. (2000) "The "Anthropocene"”. Global Change Newsletter, 41, 17-18. Recuperado de: http:/www.igbp.net/download/18.31 6f18321323470177580001401/1376383088452/NL41.pdf

Doulton, H., \& Brown, K. (2009). “Ten Years to Prevent Catastrophe? Discourses of Climate Change and International Development in the UK Press". Global Environmental Change, 19(2), pp. 191-202. https://doi.org/10.1016/j.gloenvcha.2008.10.004

Doyle, J. (2011): Mediating climate change. England: Ashgate Publishing Limited. https:// doi.org/10.7146/mediekultur.v29i55.7996

Doyle, J. (2007). "Picturing the Clima(c)tic: Greenpeace and the Representational Politics of Climate Change Communication". Science as Culture, vol 16 (jun.2007), no 2, pp.129150. https://doi.org/10.1080/09505430701368938

Duarte, C. M., Alonso, S., Benito, G., Dachs, J., Montes, C., Pardo Buendía, M., Valladares, F. (2006). Cambio Global. Impacto de la actividad humana sobre el sistema Tierra. Consejo Superior de Investigaciones Científicas. Recuperado de: http://aeclim.org/wp-content/uploads/2016/01/Cambio_global.pdf

Fernández-Reyes, R. (2010). "Irrupción mediática y representación ideológica del cambio climático en España”. En Contribuciones a las Ciencias Sociales. https://doi.org/10.4185/ RLCS-2017-1213

Fernández-Reyes, R. (director), Mancinas-Chávez, R. (coordinadora) (2013), "Medios de comunicación y cambio climático", Sevilla: Fénix editora.

Recuperado de: https://www.miteco.gob.es/es/ceneam/recursos/mini-portales tematicos/2013_Medios_de_Comunicación_y_Cambio_Climático_tcm30-70523.pdf

Küpfer, N. (1991). "Esa caprichosa mirada". Revista de la Universidad Católica de Chile, vol. 7, pp. 109-120. https://doi.org/10.7764/cdi.7.336

Manzo, E. G. (2010). "Las teorías sociológicas de Pierre Bourdieu y Norbert Elias: los conceptos de campo social y habitus”. Estudios Sociológicos, pp. 383-409. Recuperado de: https://www.redalyc.org/pdf/598/59820673003.pdf

Segado-Boj, F., Díaz-Campo, J. y Navarro-Sierra, N. (2020). "Emociones y difusión de noticias sobre el cambio climático en redes sociales. Influencia de hábitos, actitudes previas 
y usos y gratificaciones en universitarios". Revista Latina de Comunicación Social, 75, 245-269. https://www.doi.org/10.4185/RLCS-2020-1425

World Meteorological Organization (2017). WMO Statement on the State of the Global Climate in 2016. Weather Climate Water. No. 1189. Switzerland. Recuperado de: https:// library.wmo.int/doc_num.php?explnum_id=3414 